\title{
Plasmid stability and antibiotic resistance of Neisseria gonorrhoea during glucose-limited continuous culture
}

\author{
C. W. KEEVIL, B. J. SPILLANE* and N. C. MAJOR† \\ Pathogenic Microbes Research Laboratory, PHLS Centre for Applied Microbiology and Research, \\ Porton Down, Salisbury, Wilts, SP4 QUG
}

\begin{abstract}
Summary. Clinical isolates of Neisseria gonorrhoeae harbouring resistance (R) plasmids of mol. wts $4.4 \times 10^{6}$ (Asian) or $3.2 \times 10^{6}$ (African) were grown in prolonged glucose-limited continuous culture to determine the segregation efficiency of each type of plasmid and their expression of penicillinase activity in the absence of antibiotic selective pressure. One strain contained the African plasmid and cryptic and conjugative plasmids, which were all retained after 96 generations in the chemostat. By contrast, the other strain lost all plasmids after 100 generations. Both strains showed increased sensitivity to a range of antibiotics, particularly to the penicillins. Loss of penicillinase activity as minimal inhibitory concentration decreased was confirmed for both strains by assaying the enzyme spectrophotometrically. Activity decreased with the number of generations and none was detectable at the time of complete plasmid loss. This decrease was apparently due to individual bacteria ceasing to produce enzyme rather than a gradual decline in production by the whole population. The sensitivities to a broad range of antibiotics also generally increased during glucose-limited growth, but one strain became more resistant to clindamycin and the other to tetracycline.
\end{abstract}

\section{Introduction}

Penicillin resistance of Neisseria gonorrhoeae is largely attributable to the production of a periplasmic TEM-1 type $\beta$ lactamase which diffuses across the outer membrane (Bergstrom et al., 1978). Its synthesis is encoded by one of two different resistance (R) plasmids: one of mol. wt (3.2-3.4) $\times$ $10^{6}$ associated with strains originating in Africa, and one of mol. wt (4.4-4.7) $\times 10^{6}$ associated with strains of Asian origin (Cannon and Sparling, 1984). Both types share $40-50 \%$ of the $3.2 \times 10^{6}$ mol. wt transposon Tn2 insert and are closely related to penicillin-resistance plasmids found in Haemophilus spp. Most gonococci also harbour a cryptic plasmid, mol. wt $2.6 \times 10^{6}$, of unknown function (Aalen and Gundersen, 1985) and some strains contain a conjugative plasmid, mol. wt $24.5 \times 10^{6}$, that can mobilise the transfer of the $R$ plasmids (Sox et al., 1978). Retention of plasmids in a population depends on the segregation efficiency as mother cells divide into daughters. This

Received 27 Oct. 1986; revised version accepted 20 Feb. 1987. Present address: * Department of Applied Biology, UWIST, Cardiff; and $†$ Biological Laboratory, University of Kent, Canterbury. can be enhanced by the selective pressure of antibiotic treatment. Nevertheless, $\beta$-lactamase production persists in vivo in the absence of antibiotic therapy and is widely established in gonococci throughout the world.

Plasmid stability has been investigated frequently by continued sub-culture of micro-organisms on agar media or during repeated cycles of batch growth in liquid media. However, Primrose et al. (1982) have eloquently argued why the factors influencing the segregation efficiency of plasmids might be elucidated more successfully by growing bacteria in the precise environments imposed during continuous culture. This alternative approach has been concentrated on plasmids of industrial interest - typically, plasmids which are good interspecies vectors and contain cloned foreign prokaryotic or eukaryotic DNA (Harris and Emtage, 1986). The hosts employed are usually well defined laboratory strains such as Escherichia coli or Bacillus subtilis. By contrast, the segregation efficiency of plasmids of clinical interest harboured by pathogens has been little studied, despite the fact that these plasmids encode for potential virulence determinants such as toxin production, resistance to host defence mechanisms, invasive factors and antibiotic resistance (Elwell and Shi- 
pley, 1980; Dougan and Fairweather, 1985; Hardman and Gowland, 1985).

An important attribute of continuous culture is that it facilitates the study of low-nutrient environments which might be encountered in the host, together with the precise control of other related parameters. It may, therefore, provide an environmentally related model (a microcosm) in which invivo behaviour of bacteria can be simulated (Bull, 1980). We have, therefore, chosen to investigate the stability and expression of the different gonococcal $\mathrm{R}$ plasmids during growth in continuous culture in the absence of antibiotic selection, to gain insight into their persistent retention in vivo. To facilitate meaningful comparison, the plasmid compositions of the clinical isolates investigated were the relatively common set of mol. wts $\left(10^{6}\right)$ $2.6,4.5$ and 24.5 and the less typical but directly analogous set of mol. wts $\left(10^{6}\right) 2 \cdot 6,3 \cdot 2$ and $24 \cdot 5$.

\section{Materials and methods}

\section{Strains and maintenance}

Clinical isolates of penicillin-resistant gonococci were kindly provided by $\mathrm{Mr}$ K. A. Witt (CAMR, Porton Down) and were confirmed to harbour the African (strain $\mathrm{KW} 1$ ) or Asian (strain KW2) R plasmids by agarose gel electrophoresis (see later). Bacteria were stored in liquid nitrogen and revived on pre-warmed, gonococcal clear typing agar (GCCT; Swanson, 1978) in a candle jar at $37^{\circ} \mathrm{C}$ to assess the presence of pili and outer-membrane proteins II. Pilation results in small, domed, highlighted (when viewed with transmitted light) colonies whereas non-pilated cells produce large, flat, non-highlighted colonies (Jephcott et al., 1971). The presence of proteins II creates colonies which are opaque and granular whereas their absence results in transparent colonies (Swanson, 1978). The pilated, transparent variants were isolated for investigation.

Laboratory strains of Escherichia coli harbouring plasmids pBR322 or pDS1109 or E. coli strain V517 harbouring eight defined plasmid species (Macrina et al., 1978) were kindly supplied by Dr C. Duggleby (CAMR, Porton Down) as freeze-dried isolates and were revived as required.

\section{Media and growth}

Gonococci were grown in continuous culture in the defined medium of Manchee et al. (1980) with the glucose and cystine concentrations modified to 1 and $0 \cdot 1 \mathrm{~g} / \mathrm{L}$, respectively, to provide glucose-limited growth (Keevil et al., 1986). The $p \mathrm{H}$ of the medium was adjusted to 7.0 with $1 \mathrm{M} \mathrm{HCl}$ and sterilised by passage through a $0 \cdot 22-\mu \mathrm{m}$ filter (Millipore). Purified isolates were grown as lawns on GCCT for $16 \mathrm{~h}$, harvested with a loop and inoculated directly into the fermenter containing fresh medium. The apparatus comprised a LH Fermentation 500 Series II modular fermenter system (Stoke Poges, Bucks) and was stirred magnetically. The dilution rate was $0.1 \mathrm{~h}^{-1}$ (equivalent to a mean generation time of $6.9 \mathrm{~h}$ ) and excess culture was removed via an overhead weir. The $p \mathrm{H}$ was maintained automatically at $7 \cdot 0 \pm 0.05$ with $2 \mathrm{M}$ $\mathrm{NaOH}$. The dissolved oxygen tension was maintained at $20 \%$ air saturation by feedback from an immersed galvanic oxygen electrode (Uniprobe, Cardiff) to the stirrer speed controller. Filtered air was introduced over the surface of the culture at $200 \mathrm{ml} / \mathrm{min}$ via the medium input port to sweep aerosol out and prevent grow-back into the medium line. All parts of the fermenter with which the medium and culture would be in contact were made of glass, polypropylene or autoclavable nylon, because the presence of trace elements in stainless steel has been shown to affect the growth of several pathogens (Novotny and Cownley, 1979; Aranha et al., 1982). The culture was, therefore, maintained at $37^{\circ} \mathrm{C}$ with an external infra-red lamp rather than the usual stainless steel heating element.

\section{Plasmid extraction}

Plasmids were extracted from gonococci or from standard strains of $E$. coli containing defined plasmids by a modification of the method of Holmes and Quigley (1981). Briefly, strains were grown as lawns on GCCT agar for $24 \mathrm{~h}$ and a small loopful was suspended in $0.1 \mathrm{ml}$ of $50 \mathrm{~mm}$ Tris- $\mathrm{HCl}$ buffer, $p \mathrm{H} 8.0$, containing sucrose $8 \%$ $\mathrm{w} / \mathrm{v}$, Triton $\mathrm{X}-1005 \% \mathrm{w} / \mathrm{v}$ and $50 \mathrm{~mm}$ EDTA (STET buffer). Alternatively, samples were obtained directly from continuous cultures and $1.5 \mathrm{ml}$ pipetted into a 2-ml Eppendorf microcentrifuge tube. This was centrifuged for $1 \mathrm{~min}$ at $12000 \mathrm{rpm}$ in an MSE Microcentaur benchtop centrifuge. The pelleted bacteria were resuspended in $0.1 \mathrm{ml}$ of STET buffer and all samples were treated with $8 \mu \mathrm{l}$ of freshly prepared lysozyme solution $(10 \mathrm{mg} / \mathrm{ml})$ for $10 \mathrm{~min}$ at room temperature. Samples were rapidly boiled for $40 \mathrm{~s}$ to precipitate contaminating chromosomal DNA. The cell debris was removed by centrifugation at $12000 \mathrm{rpm}$ for $10 \mathrm{~min}$ and the supernate carefully transferred to a similar centrifuge tube. An equal volume of isopropanol was added to the supernate which was incubated at $-20^{\circ} \mathrm{C}$ to precipitate the DNA. After $1 \mathrm{~h}$ the samples were centrifuged at $12000 \mathrm{rpm}$ for $5 \mathrm{~min}$, the supernate was carefully removed and the DNA pellet resuspended in $70 \mu \mathrm{l}$ of ethanol. The DNA was pelleted by centrifugation at $12000 \mathrm{rpm}$ in the microcentrifuge and the ethanol was carefully removed. The remaining DNA was allowed to dry in air before being dissolved in $5 \mu \mathrm{l}$ of $40 \mathrm{~mm}$ Tris-acetate buffer, $p \mathrm{H} \mathrm{8.0}$ containing $1 \mathrm{mM}$ disodium EDTA (electrophoresis buffer).

The plasmids were identified by adding 5 volumes of plasmid solution to 1 volume of bromophenol blue $0.25 \% \mathrm{w} / \mathrm{v}$ in sucrose $40 \% \mathrm{w} / \mathrm{v}$ solution and electrophoresing $5 \mu \mathrm{l}$ through horizontal agarose $(0.8 \% \mathrm{w} / \mathrm{v})$ gels $(10 \times$ $7 \mathrm{~cm}$ ) immersed in electrophoresis buffer. The gel was run at $100 \mathrm{~mA}$ for $30 \mathrm{~min}$ or until the dye had run $3-5 \mathrm{~cm}$ 
into the gel. The plasmids were visualised by immersing the gels in ethidium bromide $0.5 \mu \mathrm{g} / \mathrm{ml}$ solution in the dark at $4^{\circ} \mathrm{C}$ for $10 \mathrm{~min}$ before viewing under UV light at $300 \mathrm{~nm}$. The gels were photographed with Polaroid Type 667 landpack film and a Kodak 22A Wratten filter.

\section{Antibiotic resistance}

Penicillin resistance was monitored initially by serially diluting samples obtained from the chemostat in prewarmed GCCT medium and culturing on GCCT agar with or without a supplement of penicillin G (Sigma) $30 \mathrm{mg} / \mathrm{L}$, as described previously (Primrose et al., 1982). The difference between the numbers of colony forming units (cfu) growing on triplicate plates of both media indicated the percentage of the population which was penicillin resistant. Differences in growth on the penicillin plates were not consequences of inoculum size because a range of dilutions was investigated. Moreover, continuous cultures were checked regularly for purity by subculturing undiluted samples (up to $10^{10}$ bacteria $/ \mathrm{ml}$ ) on to GCCT agar in the presence or absence of penicillin. Good growth was evident on penicillin agar at the start of continuous culture experiments but none was detectable with this high concentration of cells after prolonged glucose limitation. This was confirmed by picking 100 colonies from the agar medium lacking penicillin and subculturing on to agar medium containing penicillin. Percentages of survivors identical with those observed by the first method were noted.

Alternatively, continuous culture samples were diluted to $10^{5}$ bacteria $/ \mathrm{ml}$ in pre-warmed GCCT medium in Sensititre ${ }^{\circledR}$ plates (Gibco) to determine the minimal inhibitory concentration (MIC) for a range of antibiotics. The plates were incubated in a candle jar at $37^{\circ} \mathrm{C}$ for $24 \mathrm{~h}$ and examined for the presence or absence of turbidity, indicating growth. The cut-off point at which no growth was detectable in each row of wells indicated the MIC. No growth occurred in the negative wells on further incubation. Subculture of samples from the turbid wells on GCCT agar for $24 \mathrm{~h}$ at $37^{\circ} \mathrm{C}$ confirmed the presence of viable gonococci which were not contaminated with other species. A decrease in the penicillin MIC was confirmed by absence of growth on GCCT agar containing penicillin at a concentration of only $1 \mathrm{mg} / \mathrm{L}$ whereas penicillin-resistant gonococci grew on media containing penicillin $30 \mathrm{mg} / \mathrm{L}$.

\section{Penicillinase activity}

$\beta$-Lactamase production was assessed by two methods. (1) Colonies grown on agar plates for $24 \mathrm{~h}$ at $37^{\circ} \mathrm{C}$ were flooded with the chromogenic cephalosporin, nitrocefin (Glaxo), at a concentration of $0.5 \mathrm{mg} / \mathrm{ml}$ and the proportion that turned red was noted. These proportions were identical to the percentage of the population able to grow on penicillin agar (described earlier). (2) The specific penicillinase activity was measured by incubating $50 \mu \mathrm{l}$ of the nitrocefin solution with $3 \mathrm{ml}$ of culture (diluted

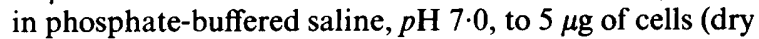
$\mathrm{wt}) / \mathrm{ml}$ ) at room temperature and following the rate of change in absorbance. The millimolar extinction coefficient for nitrocefin at $486 \mathrm{~nm}$ was $21 \cdot 1$ (O'Callaghan et al., 1972).

\section{Results}

\section{Plasmid content}

The extraction procedure of Holmes and Quigley (1981) gave good recoveries of plasmids from the standard $E$. coli strains and from clinical isolates of $N$. gonorrhoeae grown on agar or in continuous culture. Comparison with the $E$. coli plasmids indicated that the penicillin-resistant strain of $N$. gonorrhoeae, $\mathrm{KW}$, harboured an African-type $\mathrm{R}$ plasmid of mol. wt $3.5 \times 10^{6}$, together with the cryptic plasmid of mol. wt $2.6 \times 10^{6}$ and a highmol. wt plasmid of approximately $24.5 \times 10^{6}$ which was probably the conjugative plasmid (data not shown). By contrast, penicillin-resistant strain KW2 harboured an Asian-type R plasmid of mol. wt $4.8 \times 10^{6}$, together with the cryptic plasmid of mol. wt $2.6 \times 10^{6}$ and the conjugative plasmid of mol. wt $24.5 \times 10^{6}$. Other penicillin-sensitive clinical isolates tested lacked the R plasmids. However, the interpretation of the number of plasmids present in different strains of bacteria must always be regarded with some caution. The presence of multiple plasmid bands can be confusing because, depending on the extraction procedure, a single plasmid might occur in the open circular or closed circular forms; the latter migrates the faster. This possibility was investigated by electrophoresing the plasmids in one dimension and irradiating them with short wavelength light in the presence of ethidium bromide, before electrophoresing in the second dimension (Hintermann et al., 1981). This procedure converts all the closed circular material to the open circular form so that if any bands comigrate in the second dimension they are probably the same plasmid with different original configurations. No evidence of co-migration was obtained for any of the major gonococcal plasmid bands resolved in this study.

\section{Segregation of plasmids in continuous culture}

Continuous cultures of strain $\mathrm{KW} 1$ retained the African, cryptic and conjugative plasmids during prolonged glucose limitation. These plasmids were still detectable in gonococci after 96 generations. In contrast, strain KW2 apparently lost its conjugative plasmid after only 30 generations, although the Asian and cryptic plasmids were still detectable at that stage. However, no plasmids were detected after 100 generations. 


\section{Antibiotic sensitivity}

Both gonococcal strains were initially able to grow on agar containing penicillin $30 \mathrm{mg} / \mathrm{L}$. However, they became progressively incapable of growth on medium supplemented with penicillin $G$ at concentrations of either 1 or $30 \mathrm{mg} / \mathrm{L}$ after prolonged continuous culture with glucose limitation. This apparent increase in sensitivity to penicillin was confirmed by the Sensititre microdilution procedure for MIC determinations. The sensitivities of both strains to a range of antibiotics increased, particularly to the family of penicillins (table). The least inhibitory of these was oxacillin. Cephalosporin sensitivity also increased, and cefoxitin remained the most inhibitory of this class of antibiotics. Interestingly, whilst sensitivities to a broad range of antibiotics generally increased, strain KW1 became more resistant to clindamycin whereas strain $\mathrm{KW} 2$ became more resistant to tetracycline and the MIC for chloramphenicol remained unchanged.

\section{Penicillinase production}

Spectrophotometric assay showed that penicillinase activity of continuous cultures decreased slowly during the first 80 generations (fig. 1). Thereafter, the activity decreased rapidly until none was detectable by 100 generations, the approximate time of complete plasmid loss.

Gonococci recovered on agar media were exposed to an overlay of nitrocefin to determine the proportion of colonies expressing penicillinase activity. The results indicated that the decreased penicillinase production by cultures was due to individual bacteria ceasing production (fig. 2). At the commencement of glucose-limited continuous culture, all the bacteria expressed penicillinase activity. However, the numbers expressing penicillinase decreased gradually for approximately 70 generations, after which they declined sharply. This was particularly so for strain KW2 harbouring the Asian R plasmid. The ability of individual colonies to produce penicillinase was reflected in a similar proportion of the populations able to grow on penicillin agar at various times after recovery from prolonged glucose-limited continuous culture. No recovered gonococcal colonies reacted with the nitrocefin by 100 generations.

\section{Discussion}

Although isolates of $N$. gonorrhoeae were found to be resistant to penicillin as early as 1943 (Parker,
Table. Variations in the antibiotic sensitivity of $N$. gonorrhoeae harbouring the African or Asian R plasmids during prolonged glucose-limited growth in continuous culture

\begin{tabular}{|c|c|c|c|c|}
\hline \multirow[b]{3}{*}{ Antibiotic } & \multicolumn{4}{|c|}{$\begin{array}{l}\mathrm{MIC}(\mathrm{mg} / \mathrm{L}) \text { after } 45,110 \text { and } 140 \\
\text { generations of strains harbouring the } \\
\text { given plasmid }\end{array}$} \\
\hline & \multicolumn{2}{|c|}{ African } & \multicolumn{2}{|c|}{ Asian } \\
\hline & 45 & 110 & 45 & 140 \\
\hline $\begin{array}{l}\text { Penicillin } \\
\text { Carbenicillin }\end{array}$ & $\begin{array}{l}32 \\
32\end{array}$ & $\begin{array}{l}0 \cdot 5 \\
0 \cdot 5\end{array}$ & $\begin{array}{r}32 \\
128\end{array}$ & $\begin{array}{l}0.5 \\
0.5\end{array}$ \\
\hline $\begin{array}{l}\text { Cephalexin } \\
\text { Cefoxitin } \\
\text { Amikacin } \\
\text { Gentamicin } \\
\text { Erythromycin } \\
\text { Tetracycline } \\
\text { Chloramphenicol } \\
\text { Clindamycin } \\
\text { Sulphamethoxazole }\end{array}$ & $\begin{array}{c}8 \\
0 \cdot 5\end{array}$ & $\begin{array}{l}1 \\
4 \\
2\end{array}$ & $\begin{array}{l}8 \\
4 \\
4 \\
1 \\
0 \cdot 5 \\
0 \cdot 25 \\
.4 \\
2 \\
64\end{array}$ & $\begin{array}{l}4 \\
1 \\
1 \\
0 \cdot 25 \\
0 \cdot 25 \\
4 \\
4 \\
0 \cdot 125 \\
16\end{array}$ \\
\hline
\end{tabular}

1946), it was not until 1976 that penicillinase production attributable to the presence of $\mathbf{R}$ plasmids was observed (Ashford, 1976; Percival et al., 1976). Their incidence in the population has increased markedly since that time, even in areas where penicillin therapy is little used. During the 1976 outbreak in England, three women who denied further intercourse were found to harbour penicillinase-producing gonococci in the cervix 3-5 months after first isolation (Arya et al., 1984). In another woman, penicillinase-producing gonococci were isolated after she had given birth and she claimed not to have had intercourse for 8 months. This suggests that plasmids expressing penicillinase are more stable in vivo than was suggested by invitro studies in the absence of selective pressure exerted by penicillin (Roberts et al., 1977; Sparling, 1979).

The failure to contain the spread of penicillinaseproducing gonococci has raised the possibility that non-pathogenic, indigenous bacterial species could serve as alternative reservoirs for the $R$ plasmids. However, the host range for conjugation is narrow, even within the genus Neisseria, and the conjugal plasmid is not stably maintained (Genco et al., 1984). By contrast, the results presented here suggest that the segregation efficiency of plasmids and their retention in the population might instead depend on individual strains and their growth environment. For example, in the Asian strain grown in continu- 


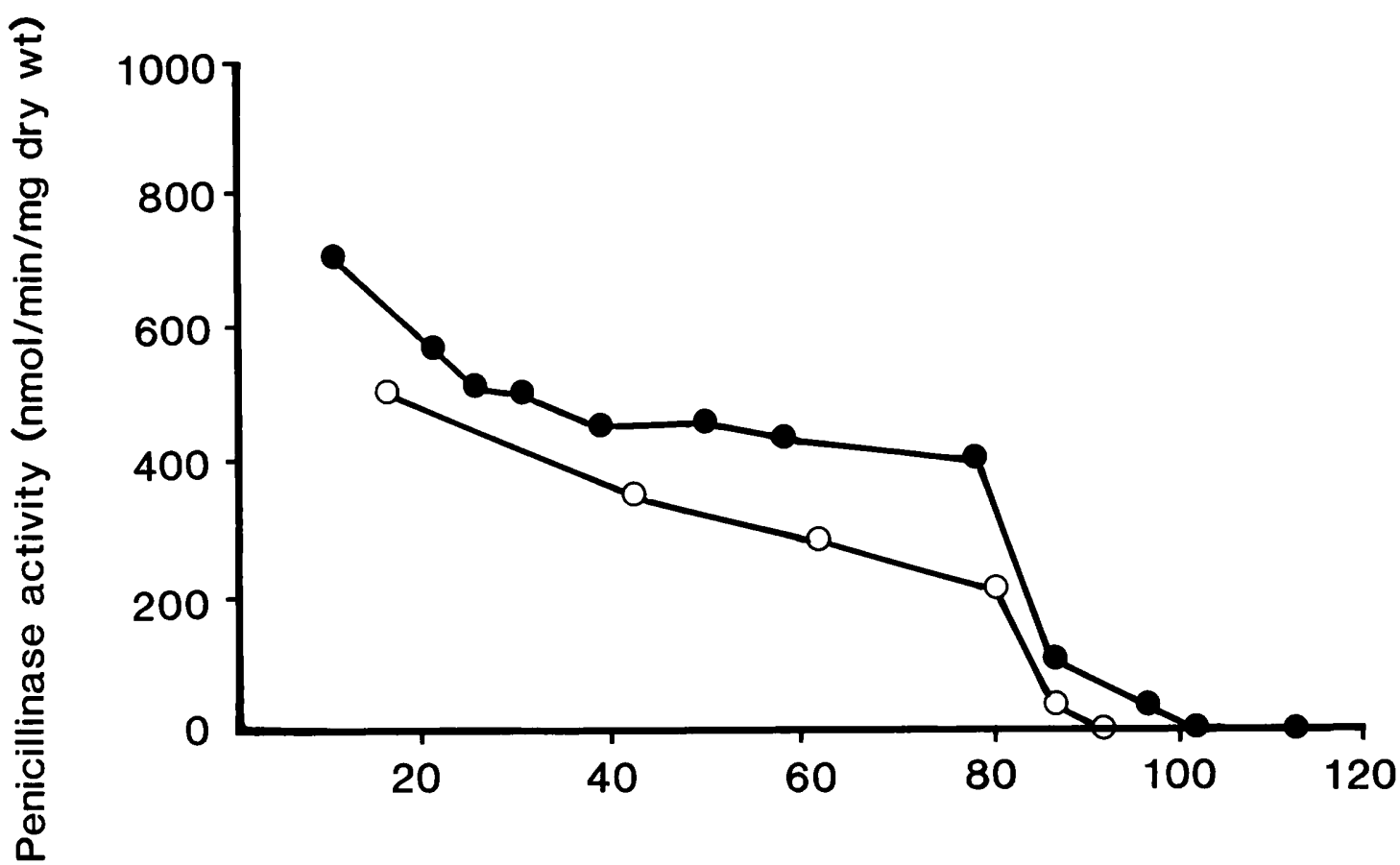

\section{Generations}

Fig. 1. Penicillinase activity of $N$. gonorrhoeae strains KW1 (O) and KW2 (O) during prolonged glucose-limited continuous culture. Samples of culture were obtained directly from the chemostat and assayed spectrophotometrically for the ability to hydrolyse nitrocefin.

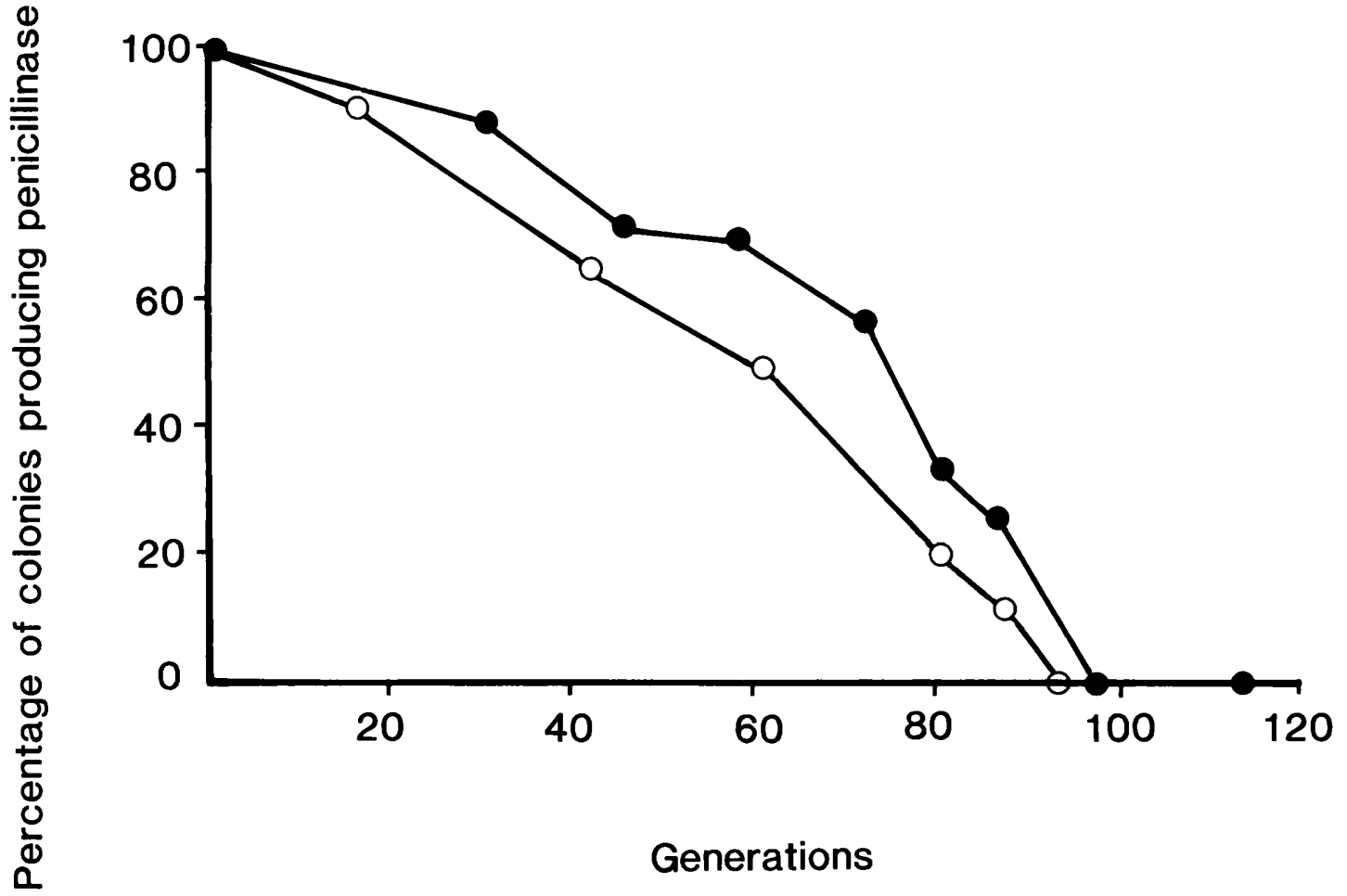

Fig. 2. Percentage of $N$. gonorrhoeae $\mathrm{KW} 1(\mathrm{O})$ and $\mathrm{KW} 2(\mathrm{O})$ colonies producing penicillinase on agar medium flooded with nitrocefin solution after prolonged glucose-limited continuous culture. 
ous culture the presence of the conjugative plasmid is not sufficient to stabilise its own retention, let alone that of the $\mathbf{R}$ plasmid. Not only is the conjugative plasmid lost rapidly but also many more generations of growth are required before complete loss of the Asian plasmid occurs. Of note also is the loss of the cryptic plasmid. This is present in almost all gonococci and, therefore, was formerly believed to be efficiently segregated (Cannon and Sparling, 1984). However, increasing numbers of clinical isolates are now being found to lack this plasmid (C.A. Ison, personal communication) casting some doubt on its stable maintenance within a population and on the importance of its function to the cell. Glucose limitation is only one of several nutrient limitations which gonococci might experience in vivo (Keevil et al., 1986). Other limitations which are currently being investigated might actually encourage the persistence of gonococcal plasmids, possibly explaining the apparent ubiquity of the enigmatic cryptic plasmid in nature.

Our chemostat data might also help explain the relative proportions of Asian and African strains found in an epidemiological study of penicillinaseproducing gonococci in the Netherlands (van Klingeren et al., 1983). The incidence of Asian strains was consistently low, irrespective of the presence or absence of the conjugative plasmid. Glucose-limited environments might be encountered frequently by gonococci growing in vivo, possibly enhancing the persistence of the African plasmid but not of the Asian plasmid. Interestingly, however, whilst all the plasmids of the African strain KW2 were retained during prolonged glucose-limited growth, penicillin resistance was lost. This might suggest that either the penicillinase gene was not expressed correctly or that the enzyme was unable to reach the target antibiotic molecules, perhaps due to changes in the cell envelope

\section{REFERENCES}

Aalen R B, Gundersen W B 1985 Polypeptides encoded by cryptic plasmids from Neisseria gonorrhoeae. Plasmid 14: 209-216.

Aranha H, Strachan R C, Arceneaux J E L, Byers B R 1982 Effect of trace metals on growth of Streptococcus mutans in a teflon chemostat. Infection and Immunity 35 : 456-460.

Arya O P et al. 1984 Epidemiology of penicillinase-producing Neisseria gonorrhoeae in Liverpool from 1977 to 1982. Journal of Infection 8: 70-83.

Ashford W A, Golash R G, Hemming V G 1976 Penicillinaseproducing Neisseria gonorrhoeae. Lancet 2: 657-658.

Bergström S, Norlander L, Norqvist A, Normark S 1978 Contribution of a TEM-1-like beta-lactamase to penicillin resistance in Neisseria gonorrhoeae. Antimicrobial Agents and Chemotherapy 13: 618-623.

Bull A T 1980 Biodegradation: some attitudes and strategies of preventing secretion (Cannon and Sparling, 1984). The latter possibility seems unlikely because the transport across the cell envelope of the majority of the antibiotics used for the MIC studies was apparently unimpaired. Interestingly, however, the MIC for clindamycin increased 4-fold for the African strain whilst the MIC for tetracycline increased 16-fold for the Asian strain. This increase in tetracycline resistance has also been found for the Asian strains in vivo (van Klingeren et al., 1983). The most common mechanism of such resistance involves chromosomal mutations affecting ribosomal function. Clindamycin inhibits peptide-bond formation by binding to $50 \mathrm{~S}$ ribosomal subunits whereas tetracycline inhibits binding of aminoacyltRNA to the A site of the $30 \mathrm{~S}$ ribosome (Pestka, 1971). Thus, mutations to the relevant ribosomal proteins prevent the binding of the antibiotics. It appears, therefore, that prolonged continuous culture affects the synthesis of ribosomal proteins, even in the absence of strong antibiotic selective pressure which would inhibit their activity. If glucose-limited continuous culture is indeed analagous to potential sites of infection for $N$. gonorrhoeae, the chromosomal mutations observed here might help account for the recent spontaneous appearance of several spectinomycin-resistant gonococci around the world which must have modified 30S ribosomal proteins (Cannon and Sparling, 1984). Thus, the ribosomal mutation hypothesis might account for the very occasional appearance of induced antibiotic resistance in a bacterial population, particularly if the recommended antibiotic therapy in current use enriches for this trait whilst killing the originally dominant sensitive population. Future work will further investigate the effects of environmental stress on the selection of antibiotic-resistant gonococci.

micro-organisms and microbiologists. In: Ellwood D C et al. (eds) Contemporary microbial ecology. Academic Press, London, pp 107-136.

Cannon J G, Sparling P F 1984 The genetics of the gonococcus. Annual Review of Microbiology 38 : 111-133.

Dougan G, Fairweather N 1985 Genetic analysis of grampositive toxin determinants: the impact of new technologies. Microbiological Sciences 2: 144-147.

Elwell L P, Shipley P L 1980 Plasmid-mediated factors associated with virulence of bacteria to animals. Annual Review of Microbiology 34: 465-496.

Genco C A, Knapp J S, Clark V L 1984 Conjugation of plasmids of Neisseria gonorrhoeae to other Neisseria species : potential reservoirs for the $\beta$-lactamase plasmid. Journal of Infectious Diseases 150: $397-401$.

Hardman D J, Gowland P C 1985 Large plasmids in bacteria. 1. A survey of associated phenotypes. Microbiological Sciences 2: 90-94. 
Harris T J R, Emtage J S 1986 Expression of heterologous genes in Escherichia coli. Microbiological Sciences 3: 28-31.

Hintermann G, Fischer H-M, Crameri R, Hütter R 1981 Simple procedure for distinguishing $\mathrm{CCC}, \mathrm{OC}$ and $\mathrm{L}$ forms of plasmid DNA by agarose gel electrophoresis. Plasmid 5: 371-373.

Holmes D S, Quigley M 1981 A rapid boiling method for the preparation of bacterial plasmids. Analytical Biochemistry 114: 193-197.

Jephcott A E, Reyn A, Birch-Andersen A 1971 Neisseria gonorrhoeae. III. Demonstration of presumed appendages to cells from different colony types. Acta Pathologica et Microbiologica Scandinavica Section B 78: 437-439.

Keevil C W, Major N C, Davies D B, Robinson A 1986 Physiology and virulence determinants of Neisseria gonorrhoeae grown in glucose-, oxygen- or cystine-limited continuous culture. Journal of General Microbiology 132: 32893302.

Macrina F L, Kopecko D J, Jones K R, Ayers D J, McCowen S M 1978 A multiple plasmid-containing Escherichia coli strain: convenient source of size reference plasmid molecules. Plasmid 1 : 417-420.

Manchee R J, Wiblin C N, Robinson A 1980 Growth of Neisseria gonorrhoeae in continuous culture. FEMS Microbiology Letters 7: 115-118.

Novotny P, Cownley K 1979 Effect of growth conditions on the composition and stability of the outer membrane of Bordetella pertussis. In: Manclark C R, Hill J C (eds) International symposium on pertussis. Department of Health, Education and Welfare Publication no. 79-1830, US Government Printing Office, Washington, DC, pp 99123.
O'Callaghan C H, Morris A, Kirby S M, Shingler A H 1972 Novel method for the detection of beta-lactamases by using a chromogenic cephalosporin substrate. Antimicrobial Agents and Chemotherapy 1 : 283-288.

Parker W S 1946 Resistant gonococci. Lancet 2: 850.

Percival A J E et al. 1976 Penicillinase-producing gonococci in Liverpool. Lancet 2: 1379-1382.

Pestka S 1971 Inhibitors of ribosome functions. Annual Review of Microbiology 25 : 487-562.

Primrose S B, Derbyshire P, Jones I M, Robinson A, Ellwood D C 1982 The application of continuous culture to the study of plasmid stability. In: Dean A C R et al. (eds) Continuous culture 8: biotechnology, medicine and the environment. Ellis Horwood, Chichester, pp. 213-238.

Roberts M, Elwell L P, Falkow S 1977 Molecular characterization of two beta-lactamase-specifying plasmids isolated from Neisseria gonorrhoeae. Journal of Bacteriology 131: 557-563.

Sox T E, Mohammed W, Blackman E, Biswas G, Sparling P F 1978 Conjugative plasmids in Neisseria gonorrhoeae. Journal of Bacteriology 134: 278-286.

Sparling P F 1979 Treatment of gonorrhoea: what effect will antibiotic resistance have in the future? Sexually Transmitted Diseases 6: 120-125.

Swanson J 1978 Studies on gonococcus infection. XII. Colony color and opacity variants on gonococci. Infection and Immunity 19: 320-331.

Van Klingeren B, Van Wijngaarden L J, Dessens-Kroon M, Van Embden J D A 1983 Penicillinase-producing gonococci in the Netherlands in 1981. Journal of Antimicrobial Chemotherapy 11 : 15-20. 